\title{
Effectiveness Of Communication Board On The Level Of Satisfaction Of The Communication Pattern Among Patients On Mechanical Ventilation
}

*Hannah Aswini. D.S.

\begin{abstract}
:
Objectives: To assess the Effectiveness of communication board on the level of satisfaction of the communication pattern among patients on mechanical ventilation. Methods: Quantitative approach. Experimental posttest only design. simple random sampling technique Result:90\% of the patients in the experimental group felt little difficulty in communicating their needs and the remaining $10 \%$ of the patients feels no difficulty at all. Among control group, $93 \%$ of the patients finds extreme difficulty in communicating their needs. Conclusion: The study finding reveals that patient who uses communication board on ventilation had significant increase in the level of satisfaction incommunication
\end{abstract}

Keywords: Effectiveness, Communication Board, Mechanical Ventilation.

\section{INTRODUCTION}

Communication difficulties are too often devastating in health care setting. They can and often do, create huge barriers between patient and health care staff. Trouble communicating can be attributed to new or chronic speech and or comprehension difficulties. ${ }^{1}$ Patient regularly report instances in which communication barriers result in feeling of anxiety, fear, frustration, unrecognized pain, and overall loss of control. In some cases, patient's communication abilities are weakened due to trauma, illness or discomfort and pain. Patients on ventilators cannot speak their requests. Because they are in a weakened state and infusions in place writing become difficult and require too much effort in such sub -optimal situations, patients are faced with critical decisions $^{3}$

\section{OBJECTIVES}

- To assess the level of satisfaction in communication among patients on mechanical ventilation in experimental and controlgroup.

- To compare the level of satisfaction in communication among patient on mechanical ventilation between experimental and controlgroup.

- To associate the level of satisfaction with selected demographic variables among patient on mechanical ventilation between experimental andcontrol. 


\section{MATERIALS AND METHODS}

The study was conducted at Indira Gandhi Government General Hospital \& Research Institute, Puducherry, among 60 patients on mechanical ventilation a quantitative approach ,experimental posttest only design and simple random sampling technique was used .The tool was developed in English and Tamil. The tool has 2sections.

\section{SECTION A}

It consists of demographic variable such as age, gender, marital status, occupation, and income, indication of mechanical ventilation and diagnosis of the patient.

\section{SECTION B}

It consists of modified Menzel's ease of communication scale, structured questionnaire to assess the communication satisfaction among patients with mechanicalventilation.

It has 25 questions, under 5 domains among that 10 questions were about physical needs, 4 questions regarding psychological needs, 6 about therapeutic needs, 4 about social needs and 1 about spiritual needs Menzel's ease of communication scale is a $\mathbf{5}$ point scale.
Highest score 4 (extremely hard), 3 (hard), 2 (somewhat hard), 1 (a little hard), 0 (no hard at all). The total score is 100 .

The description of the scores indicates the following,

0-25 - Highsatisfaction

26-50 - Goodsatisfaction

51-75 - Moderatesatisfaction

76-100 - Lowsatisfaction

Reliability was tested by split-half technique using Spearman's formula. Reliability score was 0.83 . This shows that tool was reliable the data collected from the study subjects were analyzed using descriptive (frequency and percentage). $90 \%$ of the patients in the experimental group felt little difficulty in communicating their needs and the remaining $10 \%$ of the patients felt no difficulty at all. In contrast to the experimental group findings, $93 \%$ of the control group patients find extreme difficulty in communicating their needs. This clearly indicates that the patients on mechanical ventilation of the experimental group were highly satisfied with respect to communicating theirneeds.

\section{RESULT AND DISCUSSION}

Table:1 Mean and standard deviation of overall communication score and its domains of the patients by group wise.

\begin{tabular}{|c|c|c|c|c|c|c|}
\hline \multirow{2}{*}{ Variables } & \multicolumn{2}{|c|}{ Experimental group } & \multicolumn{2}{|c|}{ Control group } & \multirow{2}{*}{ F-value } & \multirow{2}{*}{ P-value } \\
\cline { 2 - 5 } & Mean & SD & Mean & SD & & \\
\hline Physical needs & 0.3667 & 0.43258 & 3.5033 & 0.48812 & .005 & $<0 . .001$ \\
\hline Physiological needs & 0.4983 & 0.44762 & 3.1833 & 0.56832 & .269 & $<0.001$ \\
\hline Therapeutic needs & 0.4444 & 0.37736 & 3.1944 & 0.48951 & .587 & $<0.001$ \\
\hline Social needs & 0.2583 & 0.40195 & 3.3250 & 0.54595 & .074 & $<0.001$ \\
\hline Spiritual needs & 0.4000 & 0.49827 & 3.3000 & 0.74971 & .574 & $<0.001$ \\
\hline Overall & 0.3920 & 0.23072 & 3.3413 & 0.20006 & .154 & $<0.001$ \\
\hline
\end{tabular}


The table no.1 shows the mean and standard deviation of the overall communication needs and its domain by group wise. The purpose of this table was mainly to compare the experimental group and control group on their level of satisfaction, after controlling the reasons for mechanical ventilator. Since indications or reason for mechanical ventilator has been significantly different between the experimental and control group, it has been included as a Covariate in the ANCOVAanalysis.

In the experimental group, the mean score obtained had been less than 0.5 , for all the domains and over all communication needs. This indicates the patients felt little difficulty in communicating their needs. In the control group, the mean score obtained had been above 3 , indicates the patients in this group felt very high difficulty in communicating their overall needs and its domains. The significant p-value of the "Group" effect of all ANCOVA test indicates even after the controlling the covariate effect, the experimental group was better than the control group in overall communication and its five domains. Hence, it was concluded that for patients with the ventilator can be provided with communication board, so that they can communicate their needs in a betterway.

Table-2 Level of satisfaction on overall communication of the patients with ventilator by groupwise.

\begin{tabular}{|c|c|c|c|c|c|c|}
\hline \multirow{2}{*}{ Variables } & \multicolumn{2}{|c|}{ Experimental group } & \multicolumn{2}{|c|}{ Control group } & \multirow{2}{*}{$\begin{array}{l}\text { Chi- } \\
\text { square } \\
\text { test value }\end{array}$} & \multirow{2}{*}{ P-value } \\
\hline & No. & $\%$ & No. & $\%$ & & \\
\hline \multicolumn{7}{|l|}{ Overall } \\
\hline High satisfaction & 3 & 10.0 & 0 & - & 60.00 & $<0.001$ \\
\hline Good satisfaction & 27 & 90.0 & 0 & - & & \\
\hline $\begin{array}{c}\text { Moderate } \\
\text { satisfaction }\end{array}$ & 0 & - & 0 & - & & \\
\hline Low satisfaction & 0 & - & 28 & 93.3 & & \\
\hline
\end{tabular}

** $\mathbf{P}<0.01$

Table no.2 shows the level of satisfaction on overall communication of the patients with ventilator by group wise. The overall communication consists of all the five domains namely physical, physiological, therapeutic, social and spiritual needs. The overall communication need consists of 25 needs. In that $90 \%$ of the patients in the experimental group felt good satisfaction in communicating their needs and the remaining $10 \%$ of the patients felt high satisfaction In contrast to the experimental study findings, $93 \%$ of the control group patients find Low satisfaction in communicating their needs. This clearly indicates the experimental study had been superior to the control group. The patients in the experimental group are highly satisfied with respect to communicate their needs while they are under the treatment on mechanicalventilation. 


\section{CONCLUSION}

From the analysis and results it was concluded that the patients during mechanical ventilation who used communication board had significant increase in the level of satisfaction in communication than the patients who had not used the communication board the present study has been supported by a series of other studies, which ensures that the communication is effective measure in improving level of satisfaction in communication.

\section{REFERENCE}

1. Patak L, et al. (2004). Patient's reports of health care practitioner interventions related to communication during mechanical ventilation. Heart and Lung,33(5):308-320.

2. Patak L., et al. (2006). Communication boards in critical care: Patient's views.Applied Nursing Research, 19(4): 182-190.
3. Harvey Pressman, Emily Newman, Juli Pearson. Communication access with in environment. Central coast children foundation and Baulder community hospital.

4. Hoit, J. D., Lohmeier, H. L., et al. (2003). Clinical ventilator adjustments thatimprove speech. Chest 124(4): 1512-1521.

5. Brown, John, Marybeth Communication Ability, Method, and Content Among Nonspeaking: Discussion American Journal of Critical Care.2004;

6. Rue M Kleinpell, Patak E, Wilson stronks A, Costello J ,Pearson c, Henneman EA,HappM B. Communication in ICU. Advance for nurses. 2008 December 10; 6:18-21

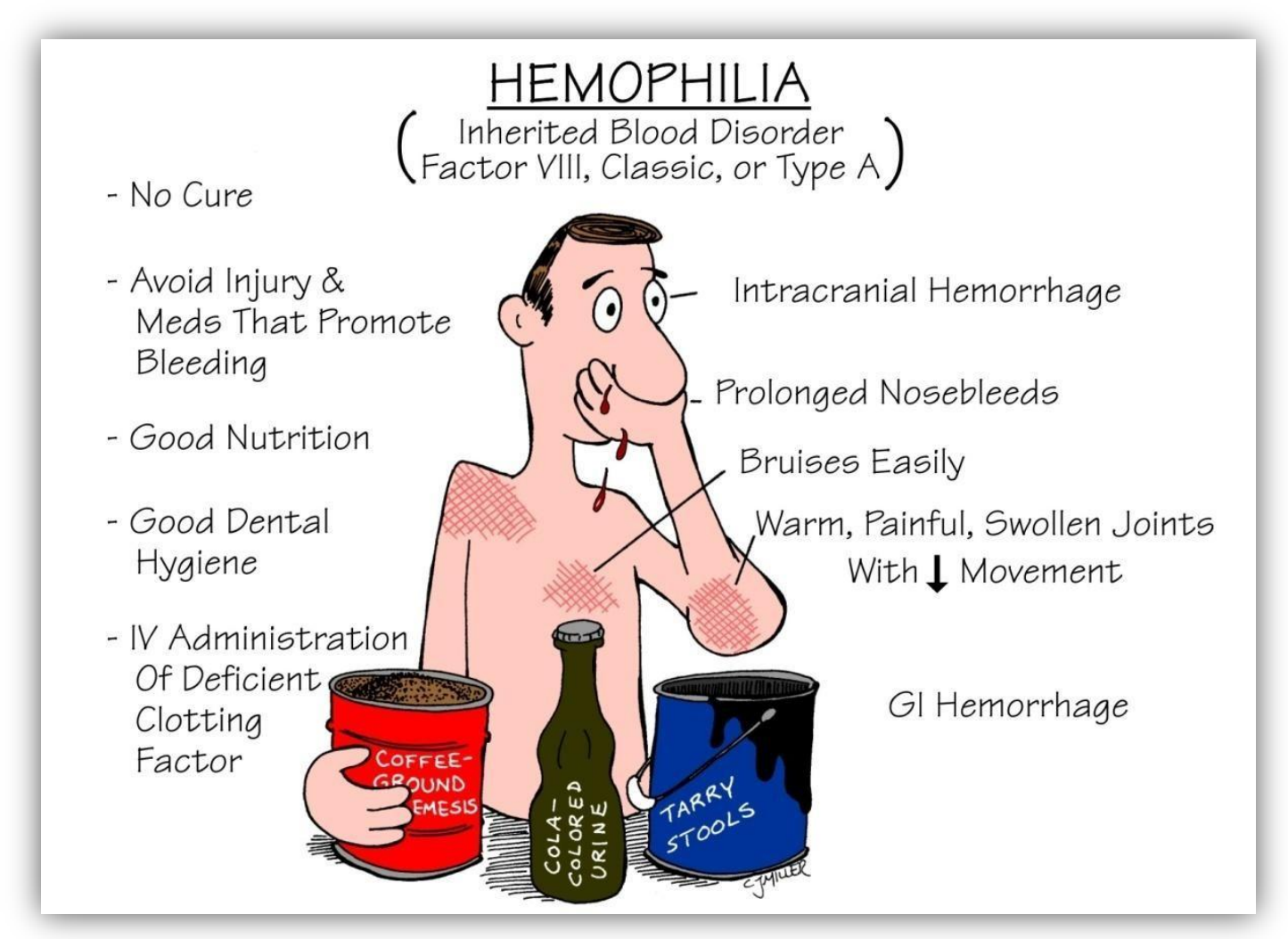

